\title{
Chemodynamics of Methyl Parathion and Ethyl Parathion: Adsorption Models for Sustainable Agriculture
}

\author{
Noshabah Tabassum, ${ }^{1}$ Uzaira Rafique, ${ }^{1}$ Khaled S. Balkhair, ${ }^{2}$ and Muhammad Aqeel Ashraf ${ }^{3}$ \\ ${ }^{1}$ Department of Environmental Sciences, Fatima Jinnah Women University, The Mall, Rawalpindi 46000, Pakistan \\ ${ }^{2}$ Department of Hydrology and Water Resources Management, King Abdulaziz University, Jeddah 22254, Saudi Arabia \\ ${ }^{3}$ Department of Geology, Centre for Research in Biotechnology for Agriculture, University of Malaya, 50603 Kuala Lumpur, Malaysia
}

Correspondence should be addressed to Muhammad Aqeel Ashraf; aqeelashraf@um.edu.my

Received 21 July 2013; Revised 4 December 2013; Accepted 24 December 2013; Published 6 February 2014

Academic Editor: Chong-Jian Tang

Copyright (c) 2014 Noshabah Tabassum et al. This is an open access article distributed under the Creative Commons Attribution License, which permits unrestricted use, distribution, and reproduction in any medium, provided the original work is properly cited.

\begin{abstract}
The toxicity of organophosphate insecticides for nontarget organism has been the subject of extensive research for sustainable agriculture. Pakistan has banned the use of methyl/ethyl parathions, but they are still illegally used. The present study is an attempt to estimate the residual concentration and to suggest remedial solution of adsorption by different types of soils collected and characterized for physicochemical parameters. Sorption of pesticides in soil or other porous media is an important process regulating pesticide transport and degradation. The percentage removal of methyl parathion and ethyl parathion was determined through UV-Visible spectrophotometer at $276 \mathrm{~nm}$ and $277 \mathrm{~nm}$, respectively. The results indicate that agricultural soil as compared to barren soil is more efficient adsorbent for both insecticides, at optimum batch condition of $\mathrm{pH}$ 7. The equilibrium between adsorbate and adsorbent was attained in 12 hours. Methyl parathion is removed more efficiently (by seven orders of magnitude) than ethyl parathion. It may be attributed to more available binding sites and less steric hindrance of methyl parathion. Adsorption kinetics indicates that a good correlation exists between distribution coefficient $(\mathrm{Kd})$ and soil organic carbon. A general increase in $\mathrm{Kd}$ is noted with increase in induced concentration due to the formation of bound or aged residue.
\end{abstract}

\section{Introduction}

Sustainable agriculture demands high and good quality food production. Increase in agricultural base has become a challenge for the growers and farmers. This compels extensive use of insecticides that lead to growing accumulation of pollutants in environment over the last decade. The environment and human health are adversely affected by irrational and high pesticides use [1]. The toxicological and ecotoxicological effect is manifested as pesticides remain chemically active and rapidly broke down into other chemicals [2]. Pesticides when applied on crops get transported to various environmental compartments [3] like soil, plant, and water, while only a small part of the chemical stays in the area where it is applied.

Organophosphates have been detected in air, snow, fog, rainwater $[4,5]$, and in the pine needles in the mountains [6], miles away from the agricultural spraying area. Toxicity of organophosphates for nontarget organisms has also been the subject of extensive research [7]. Organophosphates are extensively used in China, Colombia, and Pakistan. Use of chemicals to control pests is increasing at the rate of $25 \%$ a year [8] in Pakistan.

Organophosphates are esters of phosphoric acid and exist in two forms, Thion and Oxon [9]. Parathions (methyl and ethyl) are a group of highly toxic compounds used extensively in agricultural crops especially cotton, soybean, corn, wheat, alfalfa, vegetables, fruit trees, and domestic activities [10] leading to different hazards.

Methyl parathion, $\mathrm{C}_{8} \mathrm{H}_{10} \mathrm{NO}_{5}$ PS [11], also known as metaphos, is a broad-spectrum agricultural insecticide and acaricide that is released to the environment primarily through spraying using aircraft or ground spray equipment [12]. Methyl parathion is rapidly removed from the atmosphere [13] by wet and dry deposition and forms bound 
residues restricting its movement in soils [14-16], where its adsorption is influenced by organic matter and CEC of the soil [17]. However, its mobility and leaching into the soil-water system is affected by $\mathrm{pH}$. Methyl parathion when introduced into the environment is degraded by hydrolysis, photolysis, or microorganisms, whereas degradation appears to be significantly retarded $[18,19]$ when its concentration is high, as in bulk disposal and spills.

Ethyl parathion, $\mathrm{C}_{10} \mathrm{H}_{14} \mathrm{NO}_{5} \mathrm{PS}$, also known as thiophos, has little or no potential for groundwater contamination [11]. The major metabolites of ethyl parathion are amino parathion and 4-nitrophenol. However, in soils that have received multiple applications, 4-nitrophenol is the only metabolite and rate of degradation is faster. Soil act as a buffer and offer degradation potential for the stored pollutants with the help of soil organic carbon [20]. Pesticides also bind to soil particles thus reducing chemical availability and transportation to different environmental compartments. Chemodynamics of pesticides is generally considered to be effectively controlled through adsorption process by offering high adsorption capacity, extra ordinary surface area, and microporous structure of adsorbents.

To remediate the adverse effects and chemical accumulation of active metabolites of applied insecticides in soil fields, different control methods are in use. Solid-phase adsorption is one of the most efficient technologies for the treatment of pesticide [21].

The adsorption of organophosphorus pesticides onto activated carbon has attracted many researchers due to its high removal efficiency $[22,23]$, but high cost inhibits its application on a large scale [24].

To overcome these and other limitations associated with commercial adsorbent materials, the researchers continue their work to find out more economical and easily available materials [25] to be used as potential adsorbents.

Knowing the fact that sorption of organic chemicals to soil is a process that can affect mobility, degradation, and toxicity by reducing availability, the present investigation is designed with the following objectives:

(i) explore the use of most abundantly available soil as natural adsorbent for the removal of organophosphate pesticides;

(ii) quantify the fate and transport process of organophosphates for understanding their behavior in the environment;

(iii) determine the factors affecting binding of pesticide with soil through batch adsorption experiment.

Pakistan is a developing country with agro-based economy. Its life line and development rest on sustainable agricultural practices. Improving soil conditions of agricultural fields can ensure best growing conditions and can also offset the adverse effects of applied pesticides; for example, organic matter in soil has multiple functions. It revolves nutrient storage, improves soil structure, maintains tilt, minimizes erosion, and binds the unwanted chemical to be removed thereafter.
TABle 1: Physiochemical analysis of soil fields.

\begin{tabular}{|c|c|c|c|c|c|}
\hline Sample fields & $\begin{array}{l}\text { Wheat } \\
\text { field } \\
\text { (WF I) }\end{array}$ & $\begin{array}{l}\text { Wheat } \\
\text { field } \\
\text { (WF II) }\end{array}$ & $\begin{array}{l}\text { Wheat } \\
\text { field } \\
\text { (WF III) }\end{array}$ & $\begin{array}{c}\text { Barren } \\
\text { field } \\
(\mathrm{BF} \text { I) } \\
\end{array}$ & $\begin{array}{l}\text { Barren } \\
\text { field } \\
\text { (BF II) }\end{array}$ \\
\hline $\mathrm{pH}$ & 7.42 & 7.61 & 7.57 & 8.75 & 8.78 \\
\hline $\begin{array}{l}\text { Electrical } \\
\text { conductivity } \mu \mathrm{S} \text { at } \\
25^{\circ} \mathrm{C}\end{array}$ & 73.2 & 54.4 & 54.8 & 37.4 & 36.1 \\
\hline Bulk density $\mathrm{g} / \mathrm{cm}^{3}$ & 1.33 & 1.36 & 1.37 & 1.5 & 1.6 \\
\hline Organic content (\%) & 4.2 & 4.4 & 4.5 & 3.1 & 3.2 \\
\hline $\begin{array}{l}\text { Moisture content } \\
(\%)\end{array}$ & 3.7 & 2.33 & 3.5 & 5.5 & 5.1 \\
\hline
\end{tabular}

The present study will facilitate the prediction of the exposure level of humans and nontarget organisms to organophosphate pesticides and its active ingredients. The development of low cost soil adsorbent will suggest a pest control product for environmental remediation and sustainable agriculture.

\section{Materials and Methods}

Two different sampling areas of Jhelum, that is, agricultural (wheat) and barren (suburbs of wheat), were selected for sampling with the objective to represent varying organic matter. Topsoil (4-5 inches) 90 samples from agricultural and 60 of barren area were collected in X and zigzag pattern, respectively. Composite sieved $(2 \mathrm{~mm})$ soil sample of each type was prepared by mixing the subsoil samples in agate mortar and pestle. $\mathrm{pH}$ and temperature were noted on site.

Each soil sample was analyzed for physicochemical parameters of $\mathrm{pH}$, bulk density, electrical conductivity, and organic matter content following standard methods. The $\mathrm{pH}$ and $\mathrm{EC}$ of all solutions were recorded by $\mathrm{pH}$ (inoLab $\mathrm{pH}$ 720 ) and conductivity meter (con-500, Cyberscan), respectively. Color of samples was observed using Munsell color chart. Results of physicochemical parameters are summarized in Table 1.

The physicochemical characteristics of oil samples reveal that agricultural fields have relatively lower $\mathrm{pH}$ than barren. It may be related to the higher organic content due to more fulvic and humic acid. The range is generally alkaline for both classes of soil. Pakistani soil is mostly alkaline in nature ranging from 7.5 to 8.5 [26].

The low value of bulk density is indicative of higher organic matter content and large pore size [27]. Soil with higher content of organic matter is more porous and has relatively low bulk density [28].

EC of the soil sample decreases with decrease in \% age organic matter (see Table 1). It may be attributed to the fact that ionic concentration is greater in alkaline soils [29] and the higher the ionic species, the higher the conductivity [30].

2.1. Batch Adsorption. Nine series of batch experiments for each pesticide were conducted as a function of time to determine the percentage concentration of the pesticide 
removed by adsorption on each soil. The following general procedure for a batch experiment was adopted.

Aqueous solution of known concentration of the pesticide was induced to fixed mass ( $5 \mathrm{~g}$ ) of soil adsorbent, adjusted at known $\mathrm{pH}$ at room temperature. Solution $\mathrm{pH}$ was adjusted to the desired value ( $\mathrm{pH} 4,7$ and 10) by adding sodium acetate and acetic acid ( $\mathrm{pH} 4), 0.1 \mathrm{M} \mathrm{NH}_{3}$, and $\mathrm{NH}_{4} \mathrm{OH}$ for $\mathrm{pH} 7$ to 10 solutions [31].

The mixture was allowed to shake on Isothermal shaker (Lab-Companion SK-300). After regular contact time interval (one hour), pesticide was extracted using equimolar solvent mixture of acetone and n-hexane. The extracted aliquot was run on UV-Visible spectrophotometer (UV1601, Shimadzu) to determine the absorbance of the solution against blank. The concentration was calculated from standard calibration curve. The process continued till equilibrium was attained between adsorbate and adsorbent.

The same procedure was repeated for varying adjusted $\mathrm{pH}$ $(4,7$ and 10) and variable induced concentration in $\mu \mathrm{g} / \mathrm{L} \mathrm{(10,}$ 30 and 50) for each selected pesticide.

The percentage removal of methyl parathion and ethyl parathion by different soils at equilibrium is calculated using the following mass balance equation:

$$
q_{e}=\frac{C_{i}-C_{e}}{S}
$$

where $q_{e}$ is amount (in $\mu \mathrm{g} / \mathrm{kg}$ ) of the pesticide removed, $C_{i}$ is initial concentration of pesticide in solution $(\mu \mathrm{g} / \mathrm{L})$, and $C_{e}$ is equilibrium concentration of pesticide in solution $(\mu \mathrm{g} / \mathrm{L})$.

The dose concentration $S$ is expressed as $S=m / v$, where $v$ is initial volume of pesticide solution used and $m$ is mass of soil used.

$K_{d}$ and $K_{\mathrm{oc}}$ were also calculated using the following equations:

$$
K_{d}=\frac{\text { amount of pesticide in adsorbent }}{\text { amount of pesticide in solution }}
$$

(see [32]),

$$
K_{\mathrm{oc}}=\frac{K_{d}}{\mathrm{OC}}
$$

(see [33]).

$K_{d}$ is the distribution coefficient so $K_{d}=X / S$, where $X$ is the amount of adsorbent and $S$ is the amount of pesticide in solution. $K_{\mathrm{oc}}$ is the distribution coefficient of organic carbon and $\mathrm{OC}$ is the organic carbon.

2.2. Kinetic Studies. The adsorption kinetics was computed to optimize the appropriate correlation for equilibrium adsorption behavior. Rate was determined through application of first order, pseudo-first-order [34], pseudo-second-order [35], and intraparticle diffusion [36].

2.3. Adsorption Models. Adsorption models of Freundlich and Langmuir [37] are commonly used to describe the adsorption process. Equations are tabulated in Table 2.

\section{Results and Discussion}

3.1. Effect of $p H$. The effect of different $\mathrm{pH}(4,7$ and 10) on the adsorption of methyl parathion and ethyl parathion by different soil samples is studied. The results are graphically presented in Figures 1 and 2.

It is observed that $\mathrm{pH}$ has a momentous effect in adsorption capacity. In moving from $\mathrm{pH} 4$ to 7 , an increase in methyl parathion adsorption followed by a decrease at $\mathrm{pH}$ 10 is observed for agricultural and barren soil. The presence of hydronium ions on the adsorbent surface at lower $\mathrm{pH}$ may enhance the interaction of pesticide molecules with the binding sites of adsorbent material. It is further suggested that carbonaceous functional groups are dissociated at different $\mathrm{pH}$ values and consequently take part in the sorption process.

Same trend is noted for adsorption of ethyl parathion on both soil types in terms of variable $\mathrm{pH}$ (see Figure 2).

The present study behavior of organophosphates (parathion) is in contrast to Lindane and Carbofuran [38] reporting that adsorption increases with increase in $\mathrm{pH}$ of neutral molecules.

Decrease in percent adsorption with time is accompanied by a reduction in the adsorption capacity while extending to basic $\mathrm{pH}$ in both soil types. The reduction in adsorption capacity at higher $\mathrm{pH}$ is also reported by other authors [39]. It may also be attributed to the lesser adhesive forces between adsorbate and adsorbent than the cohesive forces of the adsorbate (due to alkaline soil and adjusted alkaline media).

The study concludes that $\mathrm{pH} 7$ is optimum evident to both pesticides, showing maximum removal efficiency for methyl and ethyl parathions as $83 \%$ and $80 \%$ for agricultural soil, whereas $82 \%$ and $79 \%$ for barren soil.

It reflects preference of organic matter content in agricultural soil for adsorption; the higher is the organic content, the more is the adsorption. Soil high in organic matter and clay are more adsorptive than coarse sandy soil because a clay or organic soil has more particle surface area or more sites into which pesticide can bind [40]. The closeness in percent adsorption on two types of soil at pH 7 (neutral) is highly encouraging as sustainable agricultural approach suggests that little or no modification is required in soil characteristics for optimum removal of parathion.

3.2. Effect of Concentration. In order to study the effect of concentration on adsorption, batch experiment was administered at induced pesticide concentration of 10,30 , and $50 \mu \mathrm{g} / \mathrm{L}$ for each soil type. The results are presented in Figures 3 and 4.

It is noted that adsorption potential of agricultural soil for removal of methyl and ethyl parathions is found to be $72 \%, 78 \%$, and $83 \%$ and $75 \%, 79 \%$, and $80 \%$, respectively, on increasing the concentration from 10 through 30 to $50 \mu \mathrm{g} / \mathrm{L}$ (see Figure 3).

As reported in the literature the maximum loading capacity of the adsorbent and the rate of adsorption were found to increase with increase in the pesticide initial concentration [24].

A different behavior is depicted by barren soil field samples for the removal of methyl parathion with change 
TABLE 2: Adsorption models along with their parameters.

\begin{tabular}{|c|c|c|c|}
\hline Isotherms & Linear expression & Plot & Parameters \\
\hline Langmuir (1918) & $\frac{C_{e}}{q_{e}}=\frac{1}{q_{m} K_{L}}+\frac{C_{e}}{q_{m}}$ & $\frac{C_{e}}{q_{e}} \mathrm{v} C_{e}$ & $\begin{array}{c}q_{m}=\frac{1}{\begin{array}{l}\text { slope } \\
\text { slope }\end{array}} \\
K_{L}=\frac{\text { intercept }}{\text { int }}\end{array}$ \\
\hline Freundlich (1906) & $\log q_{e}=\log K_{F}+\frac{1}{n} \log C_{e}$ & $\log q_{e} \mathrm{v} \log C e$ & $\begin{array}{c}n=\frac{1}{\text { slope }} \\
K_{F}=\text { Antilog (intercept) }\end{array}$ \\
\hline Pseudo-first-order & $\log \left(q_{e}-q_{t}\right)=\log q_{e}-\left(\frac{k_{1}}{2.303}\right) t$ & $\log \left(q_{e}-q_{t}\right) \mathrm{v} t$ & $\begin{array}{c}k_{1}=\text { slope } \\
q_{e}=\text { Antilog (intercept) }\end{array}$ \\
\hline Pseudo-second-order & $\frac{t}{q_{t}}=\frac{1}{k_{2} q_{e}^{2}}+\left(\frac{1}{q_{e}}\right) t$ & $\frac{t}{q_{t}} \mathrm{v} t$ & $\begin{array}{c}q_{e}=\text { slope } \\
h=\text { intercept } \\
k_{2}=\frac{\text { intercept }}{(\text { slope })^{2}}\end{array}$ \\
\hline Intraparticle diffusion & $q_{t}=k_{\mathrm{ip}} t^{0.5}+C$ & $q_{t} \mathrm{v} t$ & $\begin{array}{c}k_{\mathrm{ip}}=\text { slope } \\
C=\text { intercept }\end{array}$ \\
\hline
\end{tabular}

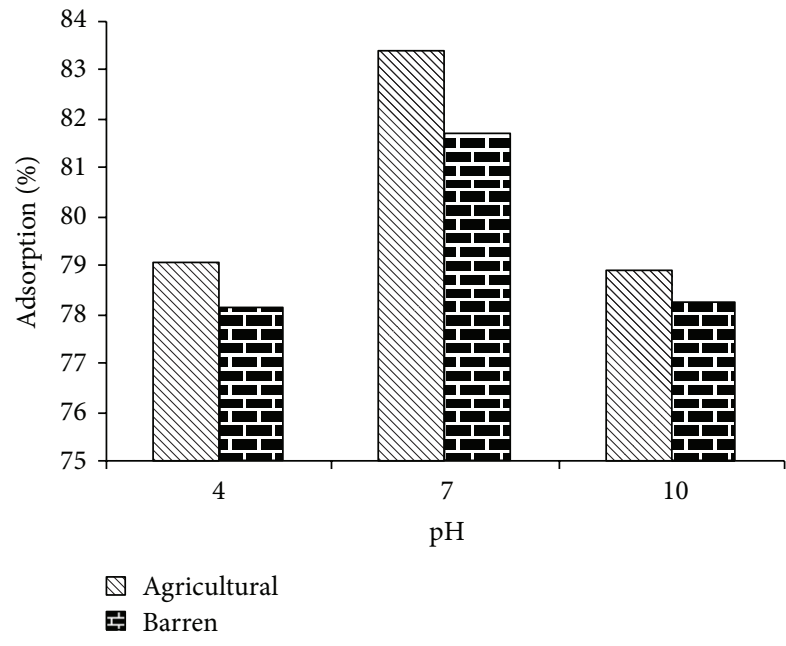

FIGURE 1: Effect of $\mathrm{pH}$ on \%-adsorption of methyl parathion.

in concentration. An initial decrease of 8 orders followed by 14 orders increase in adsorption is observed in moving from $10 \mu \mathrm{g} / \mathrm{L}$ to $50 \mu \mathrm{g} / \mathrm{L}$ (see Figure 4 ). This peculiar feature of methyl parathion adsorption is affected by the chemical properties of the pesticide [41].

The general lower adsorption behavior on barren soil is demonstrated by soil parameters like higher moisture content, significantly lower EC, and high density allowing less number of sites available.

On the other hand, barren soil behaves similarly to agricultural soil for the removal of ethyl parathion showing a gradual increase in adsorption with a regular increase in concentration. This is due to the fact that increased concentration provides necessary driving force to overcome the resistances to the mass transfer of pesticide between

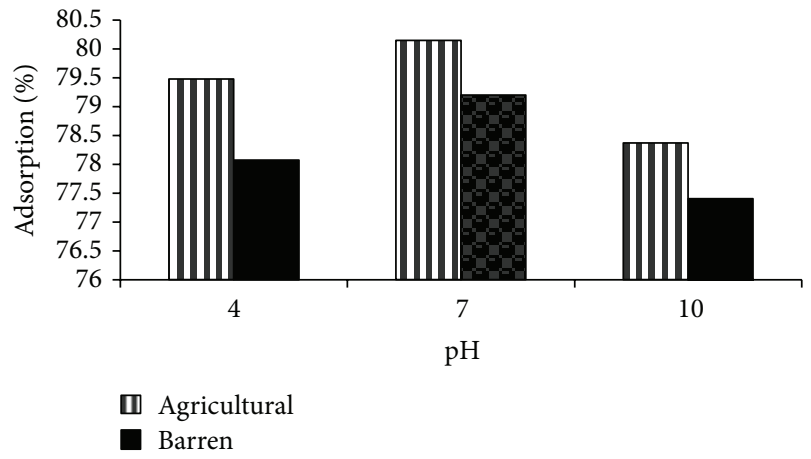

Figure 2: Effect of $\mathrm{pH}$ on \%-adsorption of ethyl parathion.

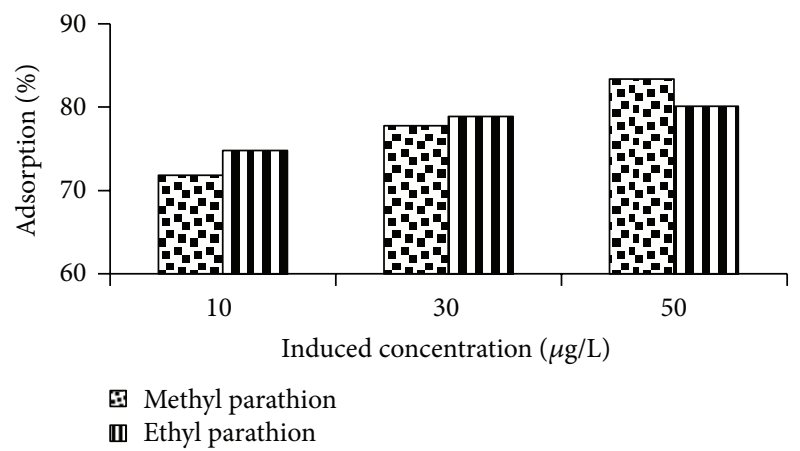

FIGURE 3: Effect of induced concentration on \%-adsorption of methyl parathion.

aqueous and solid phase. This behavior is comparable and supported by other studies [38].

The study concludes that optimum adsorption takes place at higher induced concentration $(50 \mu \mathrm{g} / \mathrm{L})$. However, the induced concentration on average impact slightly shows more 


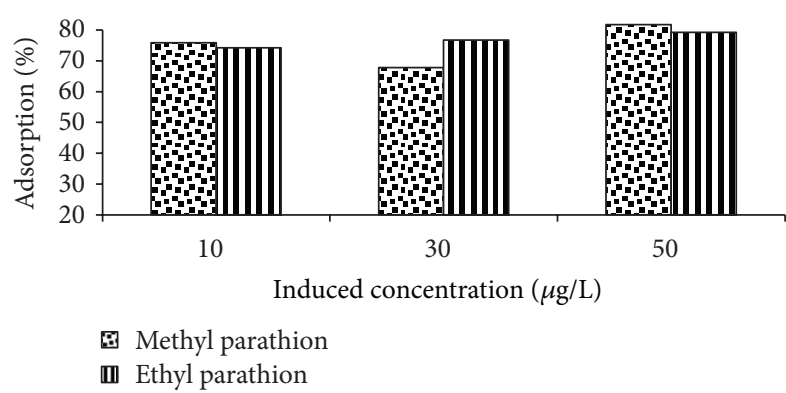

FIGURE 4: Effect of induced concentration on \%-adsorption of ethyl parathion.

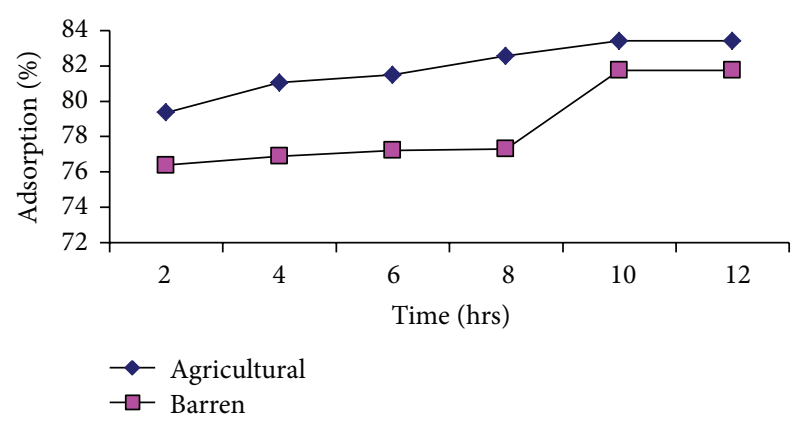

Figure 5: Effect of contact time on \%-adsorption of methyl parathion.

adsorption for methyl parathion than ethyl parathion. It may be due to insignificant structural difference between two pesticides.

3.3. Effect of Contact Time. Batch experiment was conducted with regular intervals of time in order to determine the equilibrium between adsorbate and adsorbent.

It is generally observed that adsorption increases with increase in contact time for both pesticides. The removal was rapid in early stages and finally attained almost constant value for longer contact time (see Figures 5 and 6). Obviously, the initial high adsorption rate is due to the abundance of free binding sites [24].

It is interesting to note that the first adsorption equilibrium for both pesticides is attained in 10 hours time. This is also supported by other studies. However, the rate of adsorption follows a very slow increase for barren soil till equilibrium. Agricultural soil shows a rapid increase in adsorption for the first 6 hours followed by almost the same adsorption rate till equilibrium.

3.4. Adsorption Kinetics. The average values of the adsorption kinetic parameters for both pesticides on two soil types are tabulated in Table 3.

It can be seen that pseudo-second-order kinetic fits the adsorption data equally best for both soil types and both pesticides with correlation coefficient $R^{2}(0.999)$ at optimum operating conditions of $\mathrm{pH}$ and induced concentration.

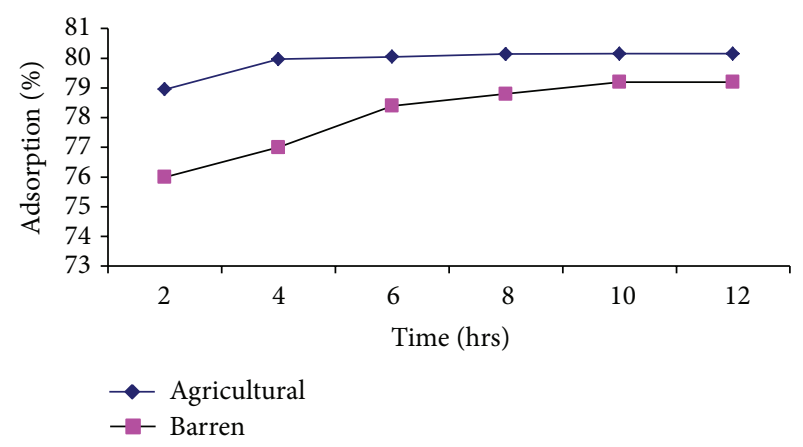

FIGURE 6: Effect of contact time on \%-adsorption of ethyl parathion.

Intraparticle diffusion kinetics also provides a good description of sorption data. A set of correlation coefficients of $0.979,0.918$ and $0.976,0.961$ is comparable for methyl and ethyl parathions on agricultural and barren soils, respectively.

It can be seen from Table 3 that distribution of methyl parathion in agricultural soil samples is comparatively higher than ethyl parathion. This is also in conformity with higher adsorption of the former on agricultural soil.

The sequence of distribution constant as a function of $\mathrm{pH}$ follows $\mathrm{pH} 7<\mathrm{pH} 4<\mathrm{pH} 10$ on agricultural and barren soil for both pesticides. On further investigation, a direct relation of $K_{d}$ and $K_{\mathrm{oc}}$ is found verifying the trend that agricultural soils are relatively proven to be better adsorbent and work optimally at $\mathrm{pH}$ 7. Direct relation of $K_{d}$ and $K_{\mathrm{oc}}$ depicting higher values for agricultural than barren soil is reported by other researchers [42] (see Table 4).

3.5. Adsorption Isotherms. Both Freundlich and Langmuir isotherms are best fit for experimental data. The magnitude of $K_{f}$ (see Table 5) shows relatively good adsorption capacity. Dada et al. reported $K_{f}$ value of $7.61 \mathrm{mg} / \mathrm{g}$ for adsorption of $\mathrm{Zn}$ onto modified rice husk [43]. Good fit of Freundlich isotherm describes that the adsorbent surface is heterogeneous in nature [44].

On the other hand, Langmuir also holds best sorption data with average $R^{2}$ (0.998). Langmuir model suggests formation of a monolayer adsorbate on the outer surface of the adsorbent and equilibrium distribution between the solid and liquid phases [45].

\section{Conclusions}

The present study concludes with the following:

(i) the batch adsorption experiment provides an efficient, convenient, and simple method for the removal of selected pesticides attaining equilibrium in 10 hours;

(ii) the parameters of paramount significance are found to be organic matter content, $\mathrm{pH}$ and induced concentration, optimum being higher organic matter, $\mathrm{pH}$ 7 , and higher $(50 \mu \mathrm{g} / \mathrm{L})$ induced concentration for the removal of both pesticides; 
TABLE 3: Kinetic models for methyl parathion and ethyl parathion.

\begin{tabular}{|c|c|c|c|c|}
\hline Soil type & Kinetic models & Parameters & $\begin{array}{c}\text { Methyl } \\
\text { parathion }\end{array}$ & Ethyl parathion \\
\hline \multirow{3}{*}{ Agricultural } & \multirow{3}{*}{ Pseudo-first-order } & $K_{1}$ & -0.0011 & -0.0011 \\
\hline & & $q_{e}$ & 2.896 & 2.8903 \\
\hline & & $R^{2}$ & 0.402 & 0.393 \\
\hline \multirow{3}{*}{ Barren } & \multirow{3}{*}{ Pseudo-first-order } & $K_{1}$ & -0.0011 & -0.0011 \\
\hline & & $q_{e}$ & 2.8813 & 2.880 \\
\hline & & $R^{2}$ & 0.3634 & 0.4023 \\
\hline \multirow{3}{*}{ Agricultural } & \multirow{3}{*}{ Pseudo-second-order } & $K_{2}$ & 0.1387 & 0.1295 \\
\hline & & $q_{e}$ & 0.0014 & 0.0011 \\
\hline & & $R^{2}$ & 0.999 & 0.999 \\
\hline \multirow{3}{*}{ Barren } & \multirow{3}{*}{ Pseudo-second-order } & $K_{2}$ & 0.0181 & 0.0255 \\
\hline & & $q_{e}$ & 0.1059 & 0.0011 \\
\hline & & $R^{2}$ & 0.5486 & 0.999 \\
\hline \multirow{3}{*}{ Agricultural } & \multirow{3}{*}{ Intraparticle diffusion } & A & 0.0098 & 0.0105 \\
\hline & & $\log K_{\mathrm{id}}$ & 1.8802 & 1.8925 \\
\hline & & $R^{2}$ & 0.979 & 0.918 \\
\hline \multirow{3}{*}{ Barren } & \multirow{3}{*}{ Intraparticle diffusion } & $A$ & 0.0064 & 0.0167 \\
\hline & & $\log K_{\mathrm{id}}$ & 1.8716 & 1.8763 \\
\hline & & $R^{2}$ & 0.976 & 0.961 \\
\hline
\end{tabular}

$q_{e}$ is in $\mu \mathrm{g} / \mathrm{L}$.

TABLE $4: K_{d}$ and $K_{\mathrm{oc}}$ values of agricultural and barren soil samples.

\begin{tabular}{|c|c|c|c|c|c|c|}
\hline & \multicolumn{3}{|c|}{$K_{d}$} & \multicolumn{3}{|c|}{$K_{\mathrm{oc}}$} \\
\hline & $\mathrm{pH} 4$ & $\mathrm{pH} 7$ & $\mathrm{pH} 10$ & $\mathrm{pH} 4$ & $\mathrm{pH} 7$ & $\mathrm{pH} 10$ \\
\hline \multicolumn{7}{|l|}{ Methyl parathion } \\
\hline Agricultural & 48.966 & 63.33 & 42.500 & 3726.71 & 3804.80 & 3079.71 \\
\hline Barren & 44.516 & 51.429 & 42.500 & 3548.23 & 3632.48 & 3413.11 \\
\hline \multicolumn{7}{|l|}{ Ethyl parathion } \\
\hline Agricultural & 63.333 & 66.957 & 53.585 & 589.37 & 851.92 & 259.78 \\
\hline Barren & 3.375 & 3.474 & 3.310 & 288.50 & 296.94 & 282.91 \\
\hline
\end{tabular}

TABLE 5: Adsorption isotherm for methyl parathion and ethyl parathion.

\begin{tabular}{|c|c|c|c|c|}
\hline Adsorption isotherm & Soil types & Parameters & Methyl parathion & Ethyl parathion \\
\hline \multirow{6}{*}{ Freundlich } & \multirow{3}{*}{ Agricultural } & $n$ & -1.606 & -1.597 \\
\hline & & $K_{f}$ & 3.25 & 3.257 \\
\hline & & $R^{2}$ & 0.999 & 0.999 \\
\hline & \multirow{3}{*}{ Barren } & $n$ & -1.602 & -1.65 \\
\hline & & $K_{f}$ & 3.325 & 3.332 \\
\hline & & $R^{2}$ & 0.999 & 0.999 \\
\hline \multirow{6}{*}{ Langmuir } & \multirow{3}{*}{ Agricultural } & $b$ & -3.325 & -3.271 \\
\hline & & $Q_{o}$ & 0.335 & 0.322 \\
\hline & & $R^{2}$ & 0.999 & 0.998 \\
\hline & \multirow{3}{*}{ Barren } & $b$ & -3.161 & -3.512 \\
\hline & & $Q_{o}$ & 0.282 & 0.332 \\
\hline & & $R^{2}$ & 0.998 & 0.995 \\
\hline
\end{tabular}


(iii) methyl parathion is found to be more effectively removed than ethyl parathion due to lower molecular weight and less steric hindrance;

(iv) pseudo-second-order, intraparticle diffusion, Langmuir and Freundlich models explain the experimental data to the best fit.

The authors propose that adsorption attains equilibrium between adsorbate and adsorbent upon contact of 10 hours. The goodness of Langmuir suggests monolayer adsorption and nature of adsorbent (soil) is determined to be heterogeneous. It also reveals that pores are not uniformly distributed. kinetics reveals that pseudo-second-order is in good agreement for agricultural soil samples suggesting its dependence on concentration of organic content. On the other hand, intraparticle diffusion is found to be equally appropriate for both soils suggesting that diffusion is not characteristics of physical characteristics of soil and pore size is the same in both soil samples.

\section{Conflict of Interests}

The authors certify that there is no conflict of interests with any financial organization regarding the material discussed in the paper.

\section{Acknowledgments}

The research was financially supported by the University of Malaya Grant nos. BKP (BK006-2013), UMRG (RG25713AFR), and FRGS (FP038-2013B).

\section{References}

[1] C. Wilson and C. Tisdell, "Why farmers continue to use pesticides despite environmental, health and sustainability costs," Ecological Economics, vol. 39, no. 3, pp. 449-462, 2001.

[2] C. P. Cai, M. Liang, and R. R. Wen, "Rapid multiresidue screening method for organophosphate pesticides in vegetables," Chromatographia, vol. 40, no. 7-8, pp. 417-420, 1995.

[3] FAO/WHO, "Joint FAO/WHO meeting on pesticide residues," WHO/PCS/96.48, World Health Organization, Geneva, Switzerland, 1996.

[4] J. R. Plimmer, "Dissipation of pesticides in the environment," in Fate of Pesticides and Chemicals in the Environment, J. L. Schnoor, Ed., pp. 79-90, Wiley-Interscience, New York, NY, USA, 1992.

[5] J. M. Zabik and J. N. Seiber, "Atmospheric transport of organophosphate pesticides from California's Central Valley to the Sierra Nevada mountains," Journal of Environmental Quality, vol. 22, no. 1, pp. 80-90, 1993.

[6] L. S. Aston and J. N. Seiber, "Exchange of airborne organophosphorus pesticides with pine needles," Journal of Environmental Science and Health B, vol. 31, no. 4, pp. 671-698, 1996.

[7] C. Bauer and J. Römbke, "Factors influencing the toxicity of two pesticides on three Lumbricid species in laboratory tests," Soil Biology and Biochemistry, vol. 29, no. 3-4, pp. 705-708, 1997.

[8] M. I. Tariq, S. Afzal, and I. Hussain, "Pesticides in shallow groundwater of Bahawalnagar, Muzafargarh, D.G. Khan and
Rajan Pur districts of Punjab, Pakistan," Environment International, vol. 30, no. 4, pp. 471-479, 2004.

[9] J. LaDou, “The asbestos cancer epidemic," Environmental Health Perspectives, vol. 112, no. 3, pp. 285-290, 2004.

[10] L. G. Costa, "Organophosphorus compounds," in Recent Advances in Nervous System Toxicology, C. L. Galli, L. Manzo, and P. S. Spencer, Eds., vol. 100 of NATO ASI Series, pp. 203246, Plenum Press, New York, NY, USA, 1988.

[11] NPIRS, National Pesticide Information Retrieval System (Database). Chemical Fact Sheet for: Methyl Parathion, U.S. Environmental Protection Agency, Office of Pesticide Programs, Washington, DC, USA, 1986, IARC 1983; NPIRS 1986; Spencer 1982.

[12] T. A. Albanis, P. J. Pomonis, and A. T. Sdoukos, "Movement of methyl parathion, lindane and atrazine through lysimeters in field conditions," Toxicological \& Environmental Chemistry, vol. 17, no. 1, pp. 35-45, 1988.

[13] M. D. Jackson and R. G. Lewis, "Volatilization of two methyl parathion formulations from treated fields," Bulletin of Environmental Contamination and Toxicology, vol. 20, no. 1, pp. 793796, 1978.

[14] W. A. Jury, A. M. Winer, W. F. Spencer, and D. D. Focht, "Transport and transformation of organic chemicals in the soilair-water ecosystems," Reviews of Environmental Contamination and Toxicology, vol. 99, pp. 119-164, 1987.

[15] J. E. McLean, R. C. Sims, and W. J. Doucette, "Evaluation of mobility of pesticides in soil using U.S. EPA Methodology," Journal of Environmental Engineering , vol. 114, no. 3, pp. 689703, 1988.

[16] K. S. Reddy and R. P. Gambrell, "Factors affecting the adsorption of 2,4-D and methyl parathion in soils and sediments," Agriculture, Ecosystems \& Environment, vol. 18, no. 3, pp. 231-241, 1987.

[17] L. C. Butler, D. C. Staiff, and J. E. Davis, "Methyl parathion persistence in soil following simulated spillage," Archives of Environmental Contamination and Toxicology, vol. 10, no. 4, pp. 451-458, 1981.

[18] EPA, "Health and environmental effects profile for methyl parathion," NTIS PB88-180534, U.S. Environmental Protection Agency, Environmental Criteria and Assessment Office, Cincinnati, Ohio, USA, 1984.

[19] M. Nousiainen, K. Peräkorpi, and M. Sillanpää, "Determination of gas-phase produced ethyl parathion and toluene 2,4diisocyanate by ion mobility spectrometry, gas chromatography and liquid chromatography," Talanta, vol. 72, no. 3, pp. 984-990, 2007.

[20] P. Burauel and F. Baßmann, "Soils as filter and buffer for pesticides-experimental concepts to understand soil functions," Environmental Pollution, vol. 133, no. 1, pp. 11-16, 2005.

[21] I. Ali and V. K. Gupta, "Adsorbents for water treatment: development of low-cost alternatives to carbon," in Encyclopedia of Surface and Colloid Science, pp. 149-184, Taylor \& Francis, New York, NY, USA, 2nd edition, 2006.

[22] H. Murayama, N. Moriyama, H. Mitobe et al., "Evaluation of activated carbon fiber filter for sampling of organochlorine pesticides in environmental water samples," Chemosphere, vol. 52, no. 5, pp. 825-833, 2003.

[23] S. J. T. Pollard, G. D. Fowler, C. J. Sollars, and R. Perry, "Lowcost adsorbents for waste and wastewater treatment: a review," Science of the Total Environment, vol. 116, no. 1-2, pp. 31-52, 1992.

[24] B. Hameed and A. Ahmad, "Batch adsorption of methylene blue from aqueous solution by garlic peel, an agricultural waste 
biomass," Journal of Hazardous Materials, vol. 164, no. 2-3, pp. 870-875, 2009.

[25] R. T. Meister, Farm Chemicals Handbook, Meister, Willoughby, Ohio, USA, 1992.

[26] Soil Survey of Pakistan, "Soil conservation and agriculture development in the Barani areas of Punjab," Lahore, Pakistan, 1975.

[27] J. P. Harsh, F. E. Koehler, C. D. Moodie, and B. L. McNeal, Laboratory Manual for Soil Analysis: Chemistry and Fertility, Department of Agronomy and Soils, Washington State University, Pullman, Wash, USA, 1988.

[28] L. M. Thompson and F. R. Troen, Soils and Soil Fertility, McGraw-Hill, New York, NY, USA, 3rd edition, 1973.

[29] A. Rashid and K. S. Memon, Soil Science, National Book Foundation, Islamabad, Pakistan, 2001.

[30] J. D. Rhoades, N. A. Manteghi, P. J. Shouse, and W. J. Alves, "Soil electrical conductivity and soil salinity: new formulations and calibrations," Soil Science Society of America Journal, vol. 53, no. 2, pp. 433-439, 1989.

[31] D. D. Perrin and B. Dempsey, Buffers for $p H$ and Metal Ion Control, Chapman \& Hall, London, UK, 1974.

[32] C. E. Beste, Herbicide Handbook of the Weed Science Society of America, vol. 3, Weed Science Society of America, Champaign, Ill, USA, 5th edition, 1983.

[33] M. Özacar, "Equilibrium and kinetic modelling of adsorption of phosphorus on calcined alunite," Adsorption, vol. 9, no. 2, pp. 125-132, 2003.

[34] F. C. Wu, R. L. Tseng, and R. S. Juang, "Kinetic modeling of liquid-phase adsorption of reactive dyes and metal ions on chitosan," Water Research, vol. 35, no. 3, pp. 613-618, 2001.

[35] E. Demirbaş, M. Kobya, S. Öncel, and S. Sencan, "Removal of $\mathrm{Ni}(\mathrm{II})$ from aqueous solution by adsorption onto hazelnut shell activated carbon: equilibrium studies," Bioresource Technology, vol. 84, no. 3, pp. 291-293, 2002.

[36] W. T. Tsai, K. J. Hsien, and J. M. Yang, "Silica adsorbent prepared from spent diatomaceous earth and its application to removal of dye from aqueous solution," Journal of Colloid and Interface Science, vol. 275, no. 2, pp. 428-433, 2004.

[37] Y. Sudhakar and A. K. Dikshit, "Competitive sorption of pesticides onto treated wood charcoal and the effect of organic and inorganic parameters on adsorption capacity;" Journal of Environmental Engineering, vol. 136, no. 10, pp. 1096-1104, 2010.

[38] Z. Al-Qodah, A. T. Shawaqfeh, and W. K. Lafi, "Adsorption of pesticides from aqueous solutions using oil shale ash," Desalination, vol. 208, no. 1-3, pp. 294-305, 2007.

[39] G. Z. Memon, M. I. Bhanger, J. R. Memon, and M. Akhtar, "Adsorption of methyl parathion from aqueous solutions using mango kernels: equilibrium, kinetic and thermodynamic studies," Bioremediation Journal, vol. 13, no. 2, pp. 102-106, 2009.

[40] K. V. Ragnarsdottir, "Environmental fate and toxicology of organophosphate pesticides," Journal of the Geological Society, vol. 157, no. 4, pp. 859-876, 2000.

[41] K. M. Spark and R. S. Swift, "Effect of soil composition and dissolved organic matter on pesticide sorption," Science of the Total Environment, vol. 298, no. 1-3, pp. 147-161, 2002.

[42] K. M. Scow, S. Fan, C. Johnson, and G. M. Ma, "Biodegradation of sorbed chemicals in soil," Environmental Health Perspectives, vol. 103, supplement 5, pp. 93-95, 1995.

[43] A. O. Dada, A. P. Olalekan, A. M. Olatunya, and O. Dada, "Langmuir, freundlich, temkin and Dubinin-Radushkevitch isotherms studies of equilibrium sorption of $\mathrm{Zn}^{2+}$ unto phosphoric acid modified rice husk," IOSR Journal of Applied Chemistry, vol. 3, no. 1, pp. 38-45, 2012.

[44] N. D. Hutson and R. T. Yang, "Theoretical basis for the Dubinin-Radushkevitch (D-R) adsorption isotherm equation," Adsorption, vol. 3, no. 3, pp. 189-195.

[45] K. R. Hall, L. C. Eagleton, A. Acrivos, and T. Vermeulen, "Pore- and solid-diffusion kinetics in fixed-bed adsorption under constant-pattern conditions," Industrial \& Engineering Chemistry Fundamentals, vol. 5, no. 2, pp. 212-223, 1966. 

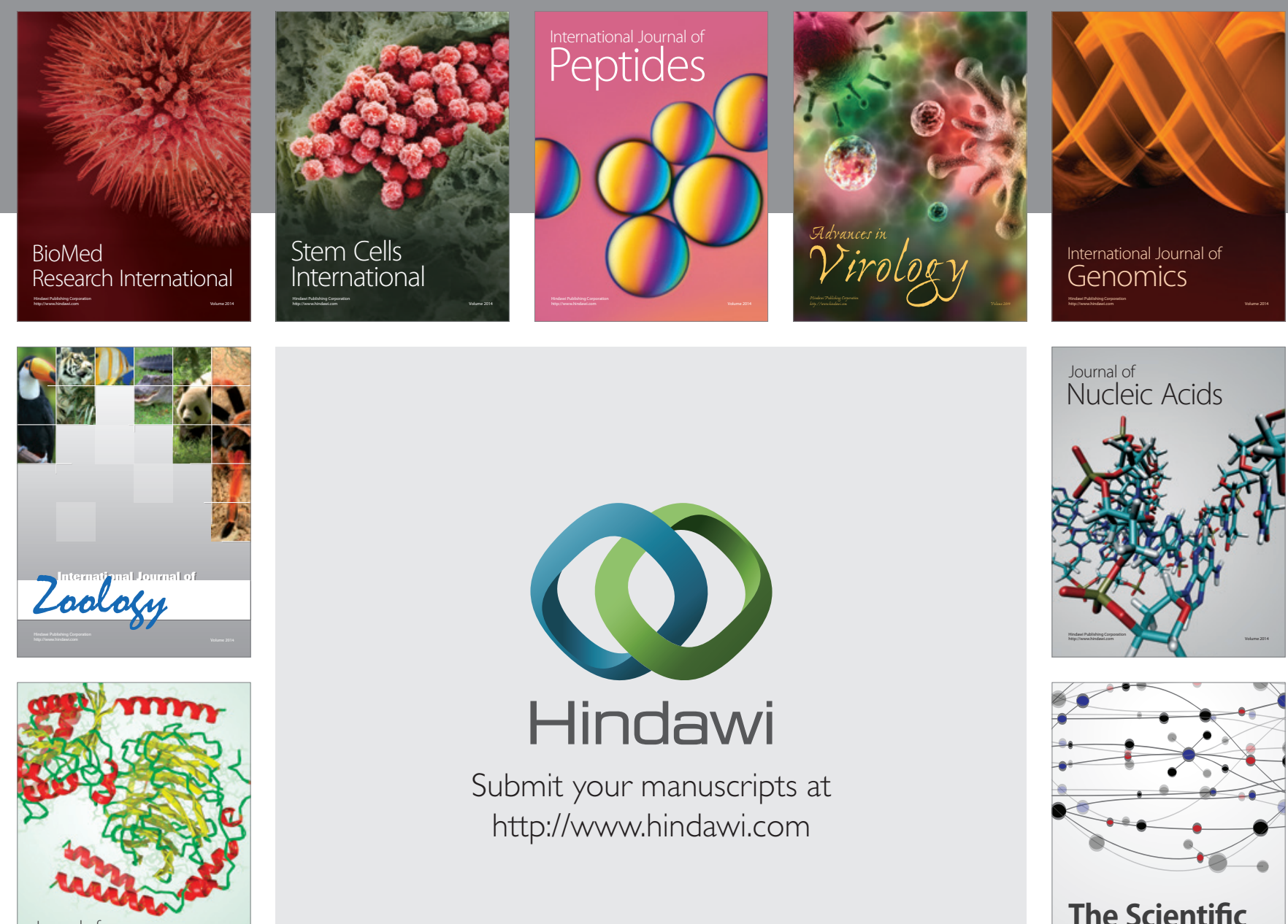

Submit your manuscripts at

http://www.hindawi.com

Journal of
Signal Transduction
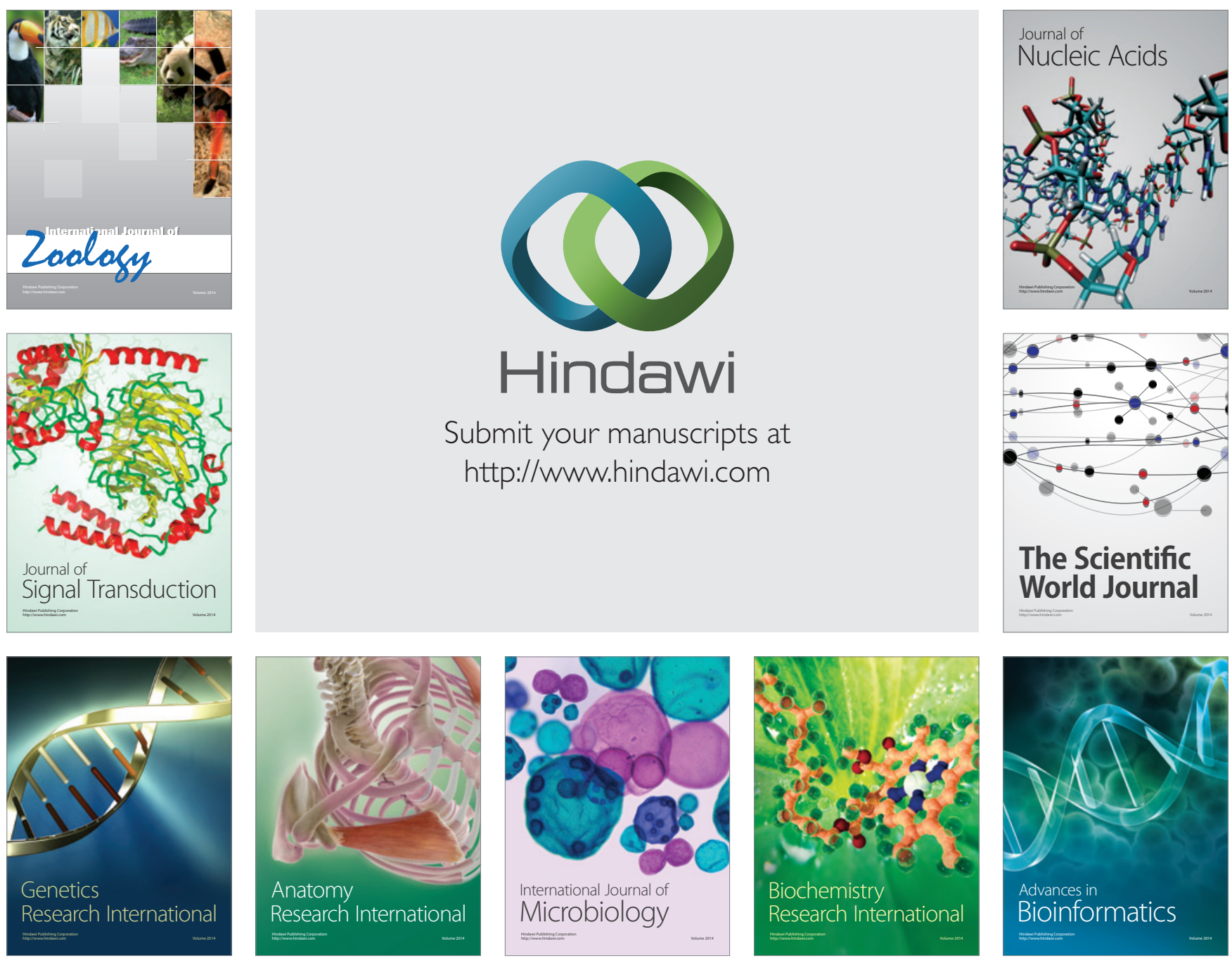

The Scientific World Journal
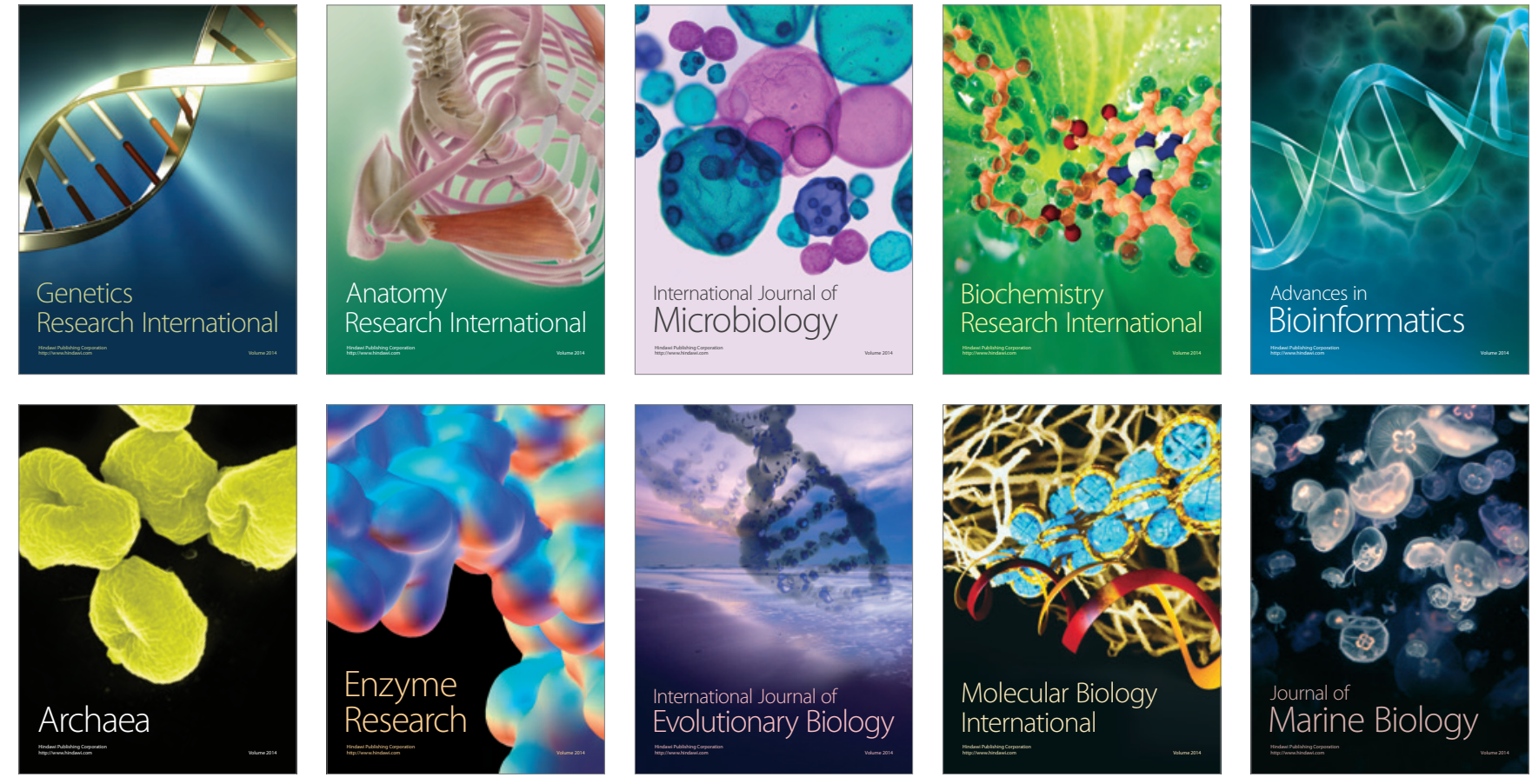